\title{
Pilot health technology assessment study: organizational and economic impact of remote monitoring system for home automated peritoneal dialysis
}

\author{
Gianpaolo Amici ${ }^{1}\left[\right.$ - Daniela D'Angela ${ }^{2} \cdot$ Antonina Lo Cicero $^{1} \cdot$ Dino Romanini $^{1} \cdot$ Francesca K. Martino $^{3}$. \\ Federico Spandonaro ${ }^{2}$
}

Received: 10 August 2020 / Accepted: 13 February 2021 / Published online: 6 March 2021

(c) The Author(s), under exclusive licence to Springer Nature B.V. part of Springer Nature 2021

\begin{abstract}
Purpose Follow-up of automated peritoneal dialysis (APD) has been improved by data transmission by cellular modem and internet cloud. With the new remote patient monitoring (RPM) technology, clinical control and prescription of dialysis are performed by software (Baxter Claria-Sharesource), which allows the center to access home operational data. The objective of this pilot study was to determine the impact of RPM compared to traditional technology, in clinical, organizational, social, and economic terms in a single center.

Methods We studied 21 prevalent APD patients aged $69 \pm 13$ years, on dialysis for a median of 9 months, for a period of 6 months with the traditional technology and 6 months with the new technology. A relevant portion of patients lived in mountainous or hilly areas.

Results Our study shows more proactive calls from the center to patients after the consultation of RPM software, reduction of calls from patients and caregivers, early detection of clinical problems, a significant reduction of unscheduled visits, and a not significant reduction of hospitalizations. The analysis also highlighted how the RPM system lead to relevant economic savings, which for the health system have been calculated $€ 335$ (mean per patient-month). With the social costs represented by the waste of time of the patient and the caregiver, we calculated $€ 685$ (mean per patient-month).

Conclusion In our pilot report, the RPM system allowed the accurate assessment of daily APD sessions to suggest significative organizational and economic advantages, and both patients and healthcare providers reported good subjective experiences in terms of safety and quality of follow-up.
\end{abstract}

Keywords Automated peritoneal dialysis $\cdot$ Remote patient monitoring $\cdot$ Cloud database $\cdot$ Telemedicine $\cdot$ Health technology assessment

Gianpaolo Amici

gianpaolo.amici@aulss4.veneto.it; amicig@tin.it

1 Nephrology and Dialysis Unit, Hospitals of San Daniele del Friuli and Tolmezzo, ASUFC Friuli Venezia Giulia, Udine, Italy

2 Facoltà di Economia, Università di Roma "Tor Vergata" and C.R.E.A. Sanità, Roma, Italy

3 Nephrology, Dialysis and Kidney Transplantation Center, San Bortolo Hospital, Vicenza and International Renal Research Institute, Vicenza, Italy

\section{Introduction}

Automated peritoneal dialysis (APD) is a dialysis modality that uses cyclers for home dialysis. The optimal follow-up of these treatments can be done using information systems that make it possible for healthcare providers to check the correct administration of dialysis. APD performed with the traditional method memorizes treatment information on removable and portable memory storage that the patient brings to the nephrology center for control and prescription modifications (Fig. 1). The limitations of this system include having to install and read a memory card and possible malfunctions with a loss of data.

In the last years, peritoneal dialysis data transmission by cellular modem and internet cloud was introduced. This 


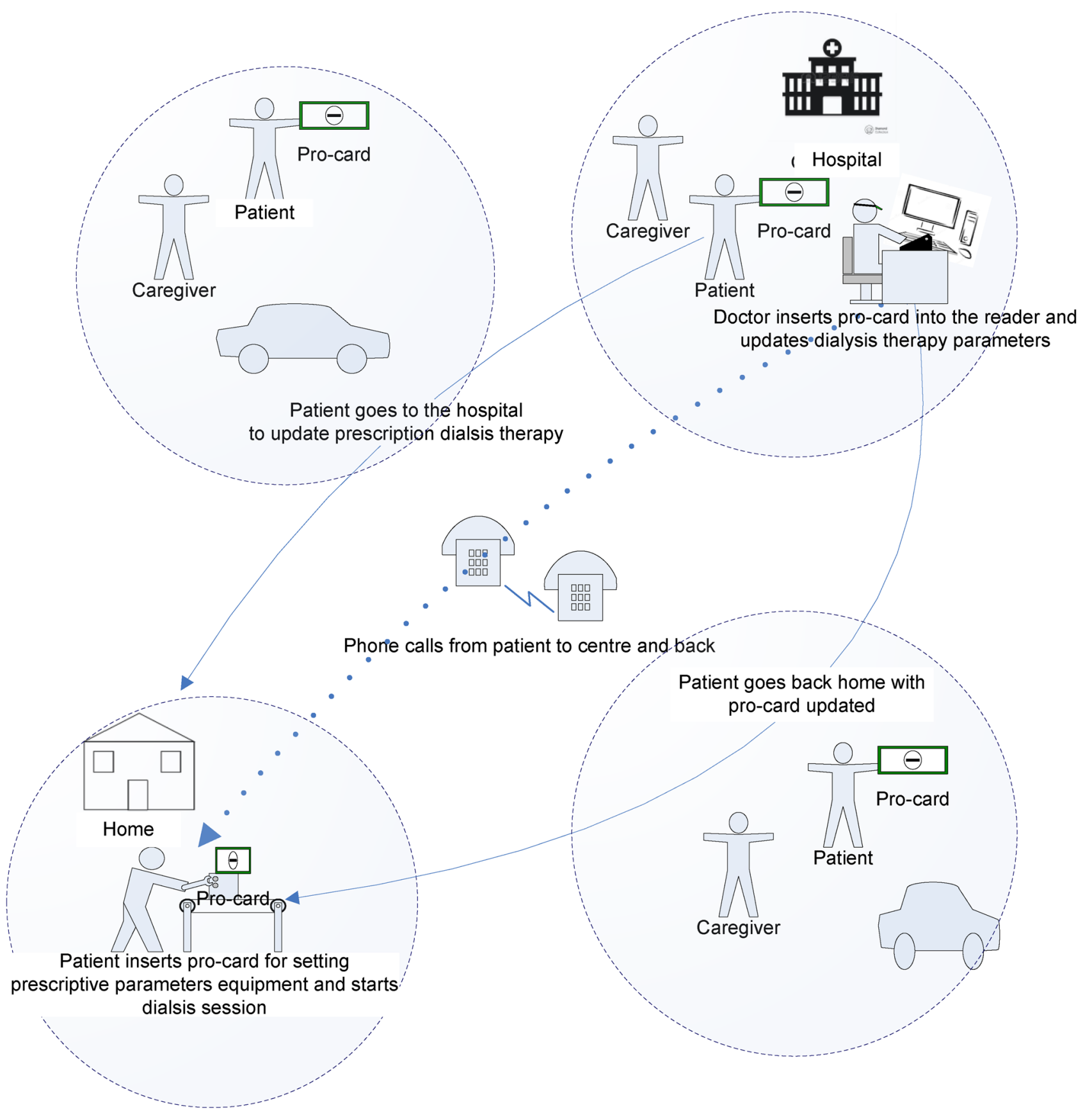

Fig. 1 Workflow of patient and operator activities with traditional APD technology Homechoice Pro and memory card

system by the bidirectional transmission of data offers the possibility of immediate consultation and remote treatment prescription modification $[1,2]$.

With the remote patient monitoring (RPM) technology (Baxter Homechoice-Claria), the prescription of dialysis is performed by entering the prescription parameters in a specific software (Baxter Sharesource), installed on the hospital intranet, which allows the nephrology center to access all home operational data (Fig. 2). This solution allows for daily monitoring of the progress of dialysis treatments in all managed patients, enabling healthcare providers to identify any non-optimal clinical parameters and, where necessary, make changes to the dialysis prescription, without having to ask the patient to come to the hospital [1,2].

The use of RPM in chronic home-care patients has been the subject of numerous published studies, which have reported significant clinical, economic, and social benefits [3-6], including a reduction in emergency room 


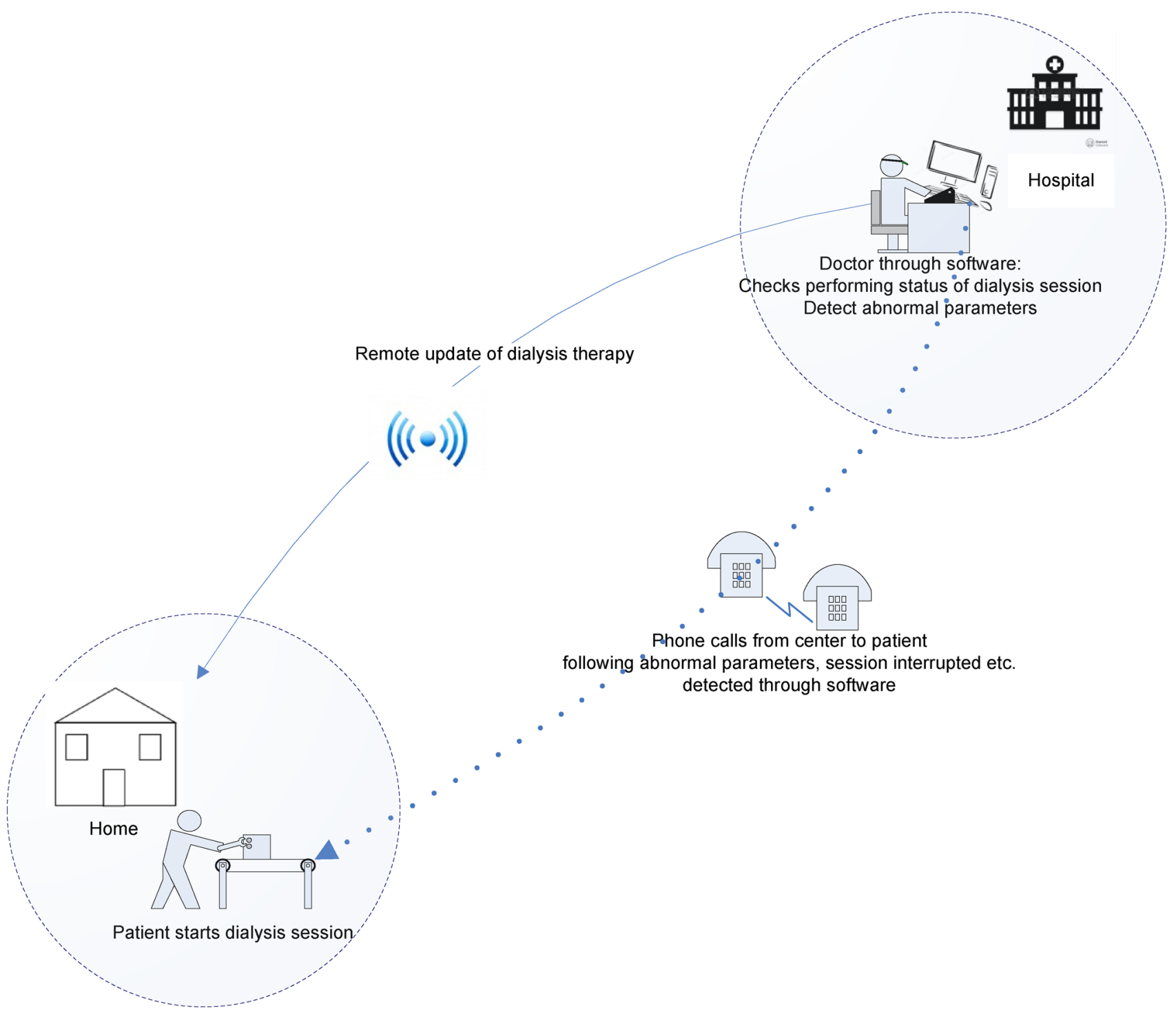

Fig. 2 Workflow of patient and operator activities with APD RPM Claria-Sharesource telemedicine technology

admissions, hospitalizations associated with treatment, and transfers from home to hospital with an improvement in the quality of care and the satisfaction of patients and their care helpers or caregivers.

The new system can improve the access to peritoneal dialysis treatments, as well as the quality of life of patients, also in large, hilly, or mountainous areas. Furthermore, the benefits in terms of safety, improvement in care, and sustainability using new remote monitoring tools may be extended even to other chronic conditions.

The objective of this pilot study was to determine the impact of the RPM telemedicine technology compared to traditional technology, in both organizational, social, and economic terms in a single center.

\section{Methods}

A comparative monocentric pilot study was designed in which all unselected prevalent patients on APD for at least 6 months were evaluated for a period of 6 months with the traditional technology and 6 months with the new technology (Fig. 3). The project and data collection did not modify in any way the patients' dialysis therapy or their scheduled clinical follow-up. The study was limited to the recording of events and an assessment of impact and the patients gave their written informed consent. The study has been designed in accordance with the Helsinki Accords and approved by the local ethical committee. 


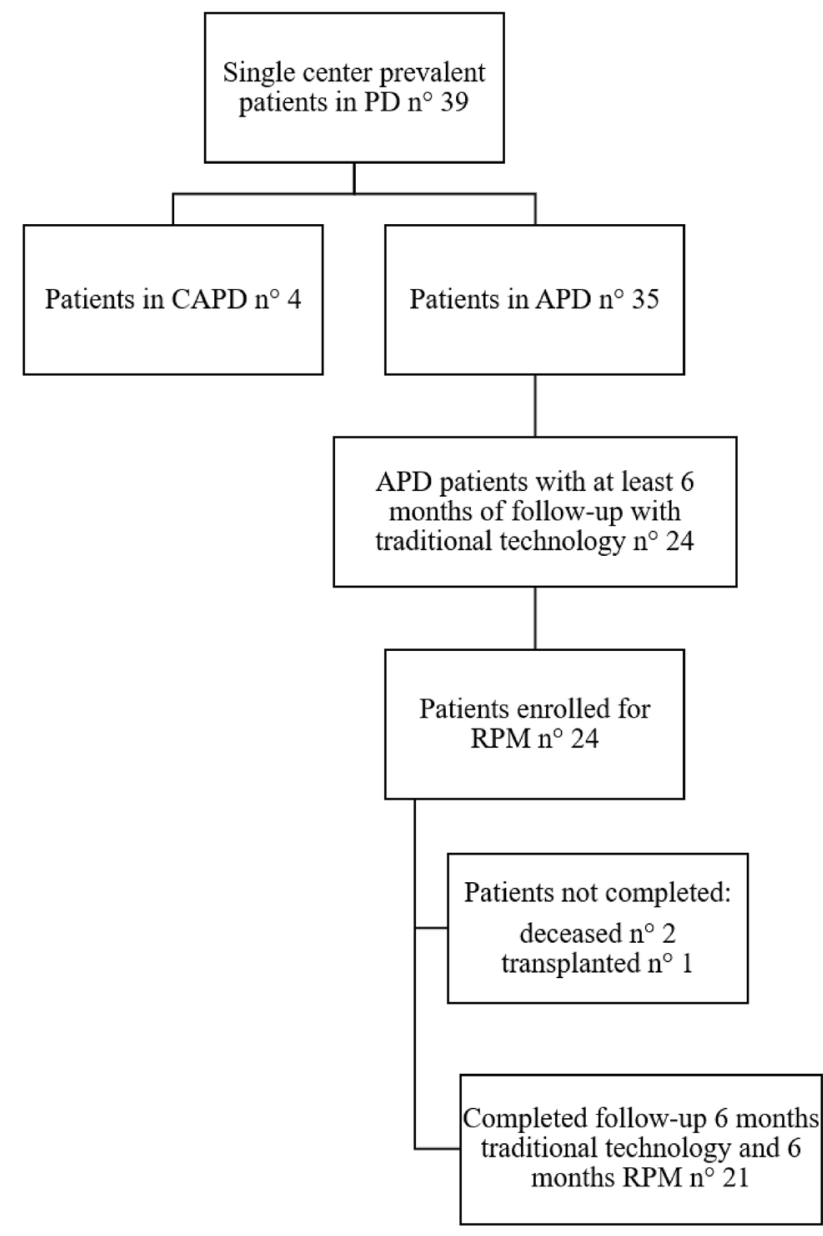

Fig. 3 Flowchart of the structure of the study

The Nephrology and Dialysis Unit of the Hospital Center of San Daniele-Tolmezzo in the Friuli Venezia Giulia Region performed the clinical part of the assessment project on the impact of the new RPM used for all patients already on APD and compared with the antecedent period with traditional cycler (HomeChoice Pro with ProCard and RenalSoft). No previous studies reported about the topic of the paper, and according to the Hertzog report [7], we considered unrealistic in term of time and cost a pilot study of more than 40 per group, so we planned a sample size between 20 and 40 .

The study included 21 patients with a mean age of $69 \pm 13$ years, sex $11 \mathrm{~F}$ and $10 \mathrm{M}$, and median time on dialysis at the start of the study was 9 months (full-range 3-67). Thirty-nine percent of patients lived in a mountainous or hilly area. The mean distance from the dialysis center was $20 \pm 17 \mathrm{~km}$.

Patients were followed over time with the following parameters: telephone calls from the dialysis center to the patient (number, duration, and reason); telephone calls from the patient to the dialysis center (number, duration, and reason); scheduled hospital visits (number, duration, reason and professional figures involved); unscheduled hospital visits both at the dialysis center and the emergency room (number, duration, reason and professional figures involved); hospitalizations (intensity of care, DRG valorization, days).

The costs of the single events were then assessed both from the perspective of the Healthcare System (HS) and from a social perspective (patient or caregiver). In particular, from the perspective of the HS, the cost of managing telephone calls was quantified with an assessment of the hourly commitment of the nurse; a similar approach was used for the cost of scheduled visits; for unscheduled hospital admissions, the time taken by the involved professionals (physicians, nurses) in providing services was calculated for every single reason for admission. Finally, as concerns hospitalizations, three different cost scenarios were proposed for assessment: (a) based on the DRG including the cost of the days beyond the cutoff; (b) based on the DRG not including the cost of the days beyond the cutoff; (c) based on the cost of days of hospitalization, categorized by medical and surgical hospitalization, including days beyond the cutoff in the calculation.

From the social perspective or that of the patient and his/ her caregiver, the cost of the telephone calls was quantified by assessing the loss of productivity of patients and caregivers. Similarly, concerning the cost of hospital admissions (hospital visits and unscheduled admissions), the direct nonmedical cost of transportation was considered, quantified based on the distance in kilometers between the patient's home and the Dialysis Center, as well as the indirect cost due to the loss of the productivity of the patient and his/her caregiver: the latter was conventionally estimated in half workdays for both, independent of the reason and duration of the visit.

Statistical analysis was performed on clinical data with non-parametric Fisher Exact test and Wilcoxon Signed-Rank test where appropriate, with JMP SAS software and the null hypothesis was rejected for alpha $<0.05$.

Furthermore, we did an estimation of the sample size of future study using the OpenEpi calculator (https://www. openepi.com/SampleSize) for comparing two means. Specifically, we compared the mean number of unplanned visits with alpha $5 \%$, power $80 \%$ and ratio sample size equal to 1 .

\section{Results}

The introduction of the new RPM technology has shown many advantages both in patients' management and cost savings. The main number of telephone calls with traditional technology was from patients to the center for various problems. While with the new technology the telephone calls were mainly proactive from the center to the patients with a significant change (Table 1). In detail, the calls from 
Table 1 Overall number and reasons of telephone calls before and after the use of the new technology

\begin{tabular}{|c|c|c|c|c|}
\hline \multirow[t]{2}{*}{ Type of events } & \multicolumn{2}{|c|}{ Period of the study with HC Pro } & \multicolumn{2}{|c|}{$\begin{array}{l}\text { Period of the study with HC } \\
\text { Claria }\end{array}$} \\
\hline & $\begin{array}{l}\text { From patient to } \\
\text { center }\end{array}$ & $\begin{array}{l}\text { From center to } \\
\text { patient }\end{array}$ & $\begin{array}{l}\text { From patient to } \\
\text { center }\end{array}$ & $\begin{array}{l}\text { From center } \\
\text { to patient }\end{array}$ \\
\hline Cycler malfunction** & 15 & 0 & 4 & 0 \\
\hline Memory card malfunction & 2 & 1 & 0 & 0 \\
\hline Disposable material malfunction & 3 & 0 & 1 & 0 \\
\hline Dialysis and catheter malfunction** & 8 & 1 & 4 & 16 \\
\hline Treatment compliance** & 0 & 0 & 0 & 10 \\
\hline Clinical data transmission & 0 & 0 & 0 & 5 \\
\hline Patient and caregiver anxiety** & 10 & 5 & 0 & 0 \\
\hline Total calls $* *$ & 38 & 7 & 9 & 31 \\
\hline
\end{tabular}

Total calls typology inversion showed a significant difference with RPM; cycler malfunction calls include problem alarms attributable to the cycler and its possible replacement, the difference with RPM was significant; memory card malfunction calls include replacements, formatting and reading problems; disposable material malfunction calls include defects in bags and sets; dialysis and catheter malfunction calls include problems with UF and slow and incomplete drainage, the difference with RPM was significant; treatment compliance calls include intentionally interrupting and skipping treatments, the difference with RPM is significant, clinical data transmission calls include the communication of tests or appointments; patient and caregiver anxiety have been subjectively referred or evaluated by the nurses and include psychological telephone support.

$* *$ Fisher Exact test $p<0.001$ the patient and caregiver for anxiety were absent with the new RPM system, whereas the calls from the center to the patients for dialysis and catheter malfunction and dialysis compliance are significantly increased (Table 1). The scheduled visits with the two systems remained practically unchanged because of the study protocol. Unscheduled visits for various causes and hospitalization days with the application of the RPM system showed a decrease, significant only for unscheduled visits (Table 2). In detail with the traditional technology, four hospital visits were due to therapy modification or card malfunction, these problems were eliminated with the new system. There is also a reduction of nursing visits as evidence that RPM can be effective to solve minor dialysis problems (Table 2).

The associated monthly cost per capita shows a relevant reduction of costs associated with telemedicine for unscheduled visits and hospitalization (Table 3). From a social perspective, the loss of productivity time for the patients and their caregivers connected to telephone calls, transportation, visits, and hospitalizations all decreased from the traditional to telemedicine systems (Table 3).

Overall, as concerns the total cost, the RPM technology, from the perspective of the HS, can offer a monthly saving per patient that ranges, depending on the used method of assessing hospitalizations (scenarios a, b, and c). From a maximum of $€ 557$ in the case of an assessment with DRG value plus the valorization of hospital days beyond the cutoff (scenario a) to a minimum value of $€ 9$ for an assessment of DRG value without the valorization of hospital days beyond the cut-off (scenario b). Finally, with the assessment simply based on days of hospitalization, a monthly saving of $€ 440$ was calculated (Table 4). The overall savings from a social perspective (direct medical and non-medical costs and indirect costs) with telemedicine thus ranged from a maximum of $€ 906$ to a minimum value of $€ 358$ monthly per patient (Table 4).

On the base of this pilot study, we esteemed the sample size of the future project for the number of unplanned visits in 116 patients.

\section{Discussion}

The switch from APD cyclers with systems based on physical media for memorizing data to RPM systems improves the availability and quality of information and allow healthcare providers to better control home dialysis. The expected improvement with the use of RPM systems concerns the daily monitoring of the progress of dialysis, with early identification of problems and consequential decrease of unplanned hospital visits and hospitalizations, supporting home care, and the safety of patients and providers. The lack of physical media, the direct transmission of dialysis data by cellular modem, the immediate consultation, and the possibility of modifying prescriptions remotely are the key features of the system in this study and offer clear potentials for optimizing healthcare, preventing complications, and saving resources [8-11]. This method of monitoring also makes it possible to record any interruptions in treatment 
Table 2 Scheduled and unscheduled hospital visits (number of events) and hospitalization days

\begin{tabular}{|c|c|c|}
\hline \multicolumn{3}{|l|}{ Hospital visits } \\
\hline Reasons for admissions & Period of the study with HC Pro & $\begin{array}{l}\text { Period of the } \\
\text { study with HC } \\
\text { Claria }\end{array}$ \\
\hline \multicolumn{3}{|l|}{ Scheduled } \\
\hline Material delivered (monthly) & 0 & 3 \\
\hline Routine visit (monthly) & 107 & 103 \\
\hline Blood tests and exams for transplant list & 21 & 35 \\
\hline Exit site dressings & 12 & 9 \\
\hline Total visits & 140 & 150 \\
\hline \multicolumn{3}{|l|}{ Unscheduled } \\
\hline Modification of dialysis therapy & 2 & 0 \\
\hline Memory card check and replacement & 2 & 0 \\
\hline Exit site infection and dressing & 22 & 11 \\
\hline Peritonitis infection and treatment & 11 & 7 \\
\hline Cycler replacement & 4 & 0 \\
\hline Materials replacement & 2 & 7 \\
\hline PD related clinical problems with nursing assessment & 16 & 10 \\
\hline Non-PD related clinical problems with nursing assessment & 15 & 8 \\
\hline PD related clinical problems with medical and nursing assessment & 10 & 12 \\
\hline Non-PD related clinical problems with medical and nursing assessment & 8 & 7 \\
\hline Total visits* & 92 & 62 \\
\hline Patients hospitalized & 2 & 2 \\
\hline Total hospitalization days & 95 & 28 \\
\hline
\end{tabular}

The number of total scheduled visits is not different; the total number of unscheduled (urgent) visits on the HC Pro period is significantly superior; visits for modification of therapy and memory card malfunction are zeroed with RPM; the number of hospitalization days on the HC Pro period is superior but not significant.

${ }^{*}$ Wilcoxon Signed-Rank test $p<0.05$

by the patient or any time the prescribed treatment is not completed as an indication of unsatisfactory compliance [2].

These advantages can be demonstrated not only in the clinical area in terms of better dialysis compliance, metabolic stability, reduction of complications but are also potential advantages in the management area with reduction of unplanned activities and hospitalizations with economic advantages as studied in an ongoing trial and simulation studies [12-14]. Indeed, the use of remote monitoring in different types of chronic home-care patients has demonstrated, in published studies, significant clinical, economic, and social benefits including a reduction in emergency room admissions, hospitalizations associated with treatment, and transfers from home to the hospital with an improvement in the quality of care and the satisfaction of the patient and his/ her care-helper or caregiver $[3,4,15,16]$.

The application of RPM has really shown its benefits in terms of easy personalization of APD therapy and also in improved technique survival, and improved quality of life in two recent interesting single-center reports in a relevant number of patients $[17,18]$.
The reported advantages of RPM in our pilot study are more proactive calls from the center to patients after the consultation of monitoring software and consequent reduction of patient and caregiver calls, early detection of problems, reduction of unscheduled visits, and tendency in the reduction of hospitalizations (Tables 1,2). The analysis also highlighted how the RPM system can lead to relevant economic savings, which for the HS have been calculated 335 euro (mean per patient-month). Considering also the social costs represented by the waste of time of the patient and the care-giver we calculated 685 euro (mean per patient-month). These savings are directly related to the unplanned events that could be avoided with the new RPM system (Tables 3, $4)$.

In our first experience, the RPM system demonstrated good functioning and a simple interface. It allowed the precise assessment of daily APD sessions and both patients and healthcare providers reported favorable subjective experiences in terms of safety and the quality of follow-up. We observed a reduction of unscheduled visits and hospitalizations and a consequent reduction of health care and social costs. Particular 
Table 3 Mean monthly event cost per patient

$\begin{array}{ll}\text { Traditional } & \text { Telemedicine } \\ \text { technology } & \text { technology }(€) \\ (€) & \end{array}$

\begin{tabular}{lrr}
\hline Direct medical costs & & \\
Telephone calls & 1 & 1 \\
Scheduled hospital visits & 54 & 31 \\
$\quad$ Unscheduled hospital visits & 14 & 1 \\
$\quad$ Hospitalizations (mean) & 273 & 122 \\
$\begin{array}{l}\text { Direct non-medical costs } \\
\quad \text { Transportation }\end{array}$ & 14 & 12 \\
$\begin{array}{l}\text { Indirect (social) costs } \\
\text { Telephone calls }\end{array}$ & 1 & 1 \\
$\quad \begin{array}{l}\text { Scheduled and unscheduled hospital } \\
\text { visits }\end{array}$ & 58 & 27 \\
$\quad$ Hospitalizations & 536 & 217 \\
$\begin{array}{l}\text { Total costs } \\
\quad \text { Telephone calls, visits, hospitaliza- } \\
\quad \text { tions and transportation }\end{array}$ & 951 & 412 \\
\hline
\end{tabular}

The assistance consumed time in minutes of all events has been quantified and converted in costs in Euro (monthly mean of 6 months). Source of cost calculation in Italy: for health workers costs ARANCCNL (Italian Agency for the Contractual Representation of the Public Administration). For social costs ISTAT database (Italian National Institute of Statistics) "National Accounts" section (http://dati.istat .it). For transportation costs see ACI (Italian Automobile Club) Tables 2016

Table 4 Reduction of overall monthly costs per patient with RPM telemedicine technology versus traditional

\begin{tabular}{lll}
\hline & $\begin{array}{l}\text { Health system perspective } \\
(€)\end{array}$ & $\begin{array}{l}\text { Social } \\
\text { perspec- } \\
\text { tive }(€)\end{array}$ \\
\hline Scenario a & -557 & -906 \\
$\begin{array}{l}\text { Scenario b } \\
\text { Scenario c }\end{array}$ & -9 & -358 \\
$\begin{array}{l}\text { Mean of the three sce- } \\
\text { narios }\end{array}$ & -440 & -790 \\
\hline
\end{tabular}

Three scenarios that differ for hospital costs calculations (Euro): a DRG including the cost of days beyond the cut-off; b DRG excluding the cost of days beyond the cut-off; c cost considering simply all hospitalization days.

satisfaction and advantages have been reported in patients living in mountainous or hilly areas. Clearly the results obtained are drawn from an analysis performed on a small number of patients and for a short time, and thus this pilot study should be considered as the first assessment for larger studies with an increase of the sample size and observation time that would be needed to support the reproducibility of the findings and the natural variability of unplanned events.
Funding This study was not funded.

\section{Compliance with ethical standards}

Conflict of interest All authors declare that they have no conflict of interest.

Ethical approval All procedures performed in studies involving human participants were in accordance with the ethical standards of the institutional and/or regional research committee and with the 1964 Helsinki declaration and its later amendments or comparable ethical standards.

Informed consent Informed consent was obtained from all individual participants included in the study.

\section{References}

1. Khangura S, Polisena J, Clifford TJ, Farrah K, Kamel C (2014) Rapid review: an emerging approach to evidence synthesis in health technology assessment. Int $\mathrm{J}$ Technol Assess Health Care 30(1):20-27. https://doi.org/10.1017/S0266462313000664 (Epub 2014 Jan 22)

2. Rojahn K, Laplante S, Sloand J, Main C, Ibrahim A, Wild J, Sturt N, Areteou T, Johnson KI (2016) Remote monitoring of chronic diseases: a landscape assessment of policies in four European countries. PLoS ONE 11(5):e0155738. https://doi.org/10.1371/ journal.pone.0155738

3. Nayak A, Karopadi A, Antony S, Sreepada S, Nayak KS (2012) Use of a peritoneal dialysis remote monitoring system in India. Perit Dial Int 32(2):200-204. https://doi.org/10.3747/ pdi.2011.00124

4. Gallar P, Vigil A, Rodriguez I, Ortega O, Gutierrez M, Hurtado J, Oliet A, Ortiz M, Mon C, Herrero JC, Lentisco C (2007) Two-year experience with telemedicine in the follow-up of patients in home peritoneal dialysis. J Telemed Telecare 13:288-292. https://doi. org/10.1258/135763307781644906

5. Nayak KS, Ronco C, Karopadi AN, Rosner MH (2016) Telemedicine and remote monitoring: supporting the patient on peritoneal dialysis. Perit Dial Int 36:362-366. https://doi.org/10.3747/ pdi.2015.00021

6. He T, Liu X, Li Y, Wu Q, Liu M, Yuan H (2017) Remote home management for chronic kidney disease: a systematic review. J Telemed Telecare 23:3-13. https://doi.org/10.1177/1357633X15 626855 (Epub 2016 Jul 9)

7. Hertzog MA (2008) Considerations in determining sample size for pilot studies. Res Nurs Health 31:180-191. https://doi. org/10.1002/nur.20247

8. Wallace EL, Rosner MH, Alscher MD, Schmitt CP, Jain A, Tentori F, Firanek C, Rheuban KS, Florez-Arango J, Jha V, Foo M, de Blok K, Marshall MR, Sanabria M, Kudelka T, Sloand JA (2017) Remote patient management for home dialysis patients. Kidney Int Rep 2:1009-1017. https://doi.org/10.1016/j.ekir.2017.07.010 (eCollection 2017 Nov)

9. Makhija D, Alscher MD, Becker S, D'Alonzo S, Mehrotra R, Wong L, McLeod K, Danek J, Gellens M, Kudelka T, Sloand JA, Laplante S (2018) Remote monitoring of automated peritoneal dialysis patients: assessing clinical and economic value. Telemed J E Health 24:315-323. https://doi.org/10.1089/tmj.2017.0046 (Epub 2017 Oct 12)

10. Drepper VJ, Martin PY, Chopard CS, Sloand JA (2018) Remote patient management in automated peritoneal dialysis: a promising 
new tool. Perit Dial Int 38:76-78. https://doi.org/10.3747/ pdi.2017.00054

11. Rosner MH, Lew SQ, Conway P, Ehrlich J, Jarrin R, Patel UD, Rheuban K, Robey RB, Sikka N, Wallace E, Brophy P, Sloand J (2017) Perspectives from the kidney health initiative on advancing technologies to facilitate remote monitoring of patient selfcare in RRT. Clin J Am Soc Nephrol 12:1900-1909. https://doi. org/10.2215/CJN.12781216 (Epub 2017 Jul 14)

12. Thilly N, Chanliau J, Frimat L, Combe C, Merville P, Chauveau P, Bataille P, Azar R, Laplaud D, Noël C, Kessler M (2017) Costeffectiveness of home telemonitoring in chronic kidney disease patients at different stages by a pragmatic randomized controlled trial (eNephro): rationale and study design. BMC Nephrol 18:126. https://doi.org/10.1186/s12882-017-0529-2

13. Uchiyama K, Washida N, Yube N, Kasai T, Shinozuka K, Morimoto K, Hishikawa A, Inoue H, Urai H, Hagiwara A, Fujii K, Wakino S, Deenitchina S, Itoh H (2018) The impact of a remote monitoring system of healthcare resource consumption in patients on automated peritoneal dialysis (APD): a simulation study. Clin Nephrol 90:334-340. https://doi.org/10.5414/CN109471

14. Garcia MAM, Rosales MSF, Dominguez EL, Velasquez YH, Dominguez IS (2018) Telemonitoring system for patients with chronic kidney disease undergoing peritoneal dialysis: usability assessment based on a case study. PLoS ONE 13:e0206600. https ://doi.org/10.1371/journal.pone.0206600
15. Sanabria M, Buitrago G, Lindholm B, Vesga J, Nilsson LG, Yang D, Bunch A, Rivera A (2019) Remote patient monitoring program in automated peritoneal dialysis: impact on hospitalizations. Perit Dial Int 2019(39):472-478. https://doi.org/10.3747/ pdi.2018.00287 (Epub 2019 Jul 23)

16. Magnus M, Sikka N, Cherian T, Lew SQ (2017) Satisfaction and improvements in peritoneal dialysis outcomes associated with telehealth. Appl Clin Inform 8:214-225. https://doi.org/10.4338/ ACI-2016-09-RA-0154

17. Manani SM, Crepaldi C, Giuliani A, Virzì GM, Garzotto F, Riello C, de Cal M, Rosner MH, Ronco C (2018) Remote monitoring of automated peritoneal dialysis improves personalization of dialytic prescription and patient's independence. Blood Purif 46:111-117. https://doi.org/10.1159/000487703 (Epub 2018 Apr 25)

18. Manani SM, Rosner MH, Virzì GM, Giuliani A, Berti S, Crepaldi C, Ronco C (2019) Longitudinal experience with remote monitoring for automated peritoneal dialysis patients. Nephron 142(1):1-9. https://doi.org/10.1159/000496182 (Epub 2019 Jan 30)

Publisher's Note Springer Nature remains neutral with regard to jurisdictional claims in published maps and institutional affiliations. 


\section{Terms and Conditions}

Springer Nature journal content, brought to you courtesy of Springer Nature Customer Service Center GmbH ("Springer Nature").

Springer Nature supports a reasonable amount of sharing of research papers by authors, subscribers and authorised users ("Users"), for smallscale personal, non-commercial use provided that all copyright, trade and service marks and other proprietary notices are maintained. By accessing, sharing, receiving or otherwise using the Springer Nature journal content you agree to these terms of use ("Terms"). For these purposes, Springer Nature considers academic use (by researchers and students) to be non-commercial.

These Terms are supplementary and will apply in addition to any applicable website terms and conditions, a relevant site licence or a personal subscription. These Terms will prevail over any conflict or ambiguity with regards to the relevant terms, a site licence or a personal subscription (to the extent of the conflict or ambiguity only). For Creative Commons-licensed articles, the terms of the Creative Commons license used will apply.

We collect and use personal data to provide access to the Springer Nature journal content. We may also use these personal data internally within ResearchGate and Springer Nature and as agreed share it, in an anonymised way, for purposes of tracking, analysis and reporting. We will not otherwise disclose your personal data outside the ResearchGate or the Springer Nature group of companies unless we have your permission as detailed in the Privacy Policy.

While Users may use the Springer Nature journal content for small scale, personal non-commercial use, it is important to note that Users may not:

1. use such content for the purpose of providing other users with access on a regular or large scale basis or as a means to circumvent access control;

2. use such content where to do so would be considered a criminal or statutory offence in any jurisdiction, or gives rise to civil liability, or is otherwise unlawful;

3. falsely or misleadingly imply or suggest endorsement, approval, sponsorship, or association unless explicitly agreed to by Springer Nature in writing;

4. use bots or other automated methods to access the content or redirect messages

5. override any security feature or exclusionary protocol; or

6. share the content in order to create substitute for Springer Nature products or services or a systematic database of Springer Nature journal content.

In line with the restriction against commercial use, Springer Nature does not permit the creation of a product or service that creates revenue, royalties, rent or income from our content or its inclusion as part of a paid for service or for other commercial gain. Springer Nature journal content cannot be used for inter-library loans and librarians may not upload Springer Nature journal content on a large scale into their, or any other, institutional repository.

These terms of use are reviewed regularly and may be amended at any time. Springer Nature is not obligated to publish any information or content on this website and may remove it or features or functionality at our sole discretion, at any time with or without notice. Springer Nature may revoke this licence to you at any time and remove access to any copies of the Springer Nature journal content which have been saved.

To the fullest extent permitted by law, Springer Nature makes no warranties, representations or guarantees to Users, either express or implied with respect to the Springer nature journal content and all parties disclaim and waive any implied warranties or warranties imposed by law, including merchantability or fitness for any particular purpose.

Please note that these rights do not automatically extend to content, data or other material published by Springer Nature that may be licensed from third parties.

If you would like to use or distribute our Springer Nature journal content to a wider audience or on a regular basis or in any other manner not expressly permitted by these Terms, please contact Springer Nature at

onlineservice@springernature.com 